\title{
Measurement of friction in a cold extrusion operation: Study by numerical simulation of four friction tests
}

\author{
Q. Zhang ${ }^{1}$, M. Arentoft ${ }^{2}$, S. Bruschi ${ }^{3}$, L. Dubar ${ }^{4}$, E. Felder ${ }^{1}$ \\ ${ }^{1}$ CEMEF, UMR CNRS/Ecole des Mines de Paris 7635, B.P. 207, F 06904 Sophia Antipolis Cedex, France \\ URL: http://www.cemef.cma.frl e-mail:qi.zhang@ensmp.fr; Eric.Felder@ensmp.fr
}

${ }^{2}$ IPU, Technical University of Denmark, Produktionstorvet, Bygning 425 DK-2800 Kgs. Lyngby, Denmark

URL: $\underline{\text { htp: } / / w w w . i p u . d k} \quad$ e-mail: ma@ipu.dk

${ }^{3}$ DIMEG, University of Padova, Via Venezia, 1-35131 Padova, Italy

URL: http://www.dimeg.unipd.it/_e-mail: bruschis@ing.unitn.it

${ }^{4}$ LAMIH, Université de Valenciennes Le Mont Houy F59313 Valenciennes Cedex 9, France

URL: http://www.univ-valenciennes.fr/LAMIH/ e-mail:laurent.dubar@univ-valenciennes.fr

\begin{abstract}
The measurement of friction in the industrial metal working operations is a complex problem because the friction test must impose at the tool/metal interface conditions similar to those in the industrial operations. So in the European Network VIF (Virtual Intelligent Forging), a workshop (WP3) was held to evaluate friction condition in cold forging by using numerical simulation and experimental methods. It was chosen an industrial cold extrusion operation, in which a low carbon steel bar, covered with phosphate layer and soap, was drawn, cropped and then formed by extrusion. In order to know the friction condition in this industrial extrusion operation, four kinds of friction tests, forward extrusion, double-cup extrusion, upsetting-sliding test and T-shape compression were carried out in four labs, IPU, DIMEG, LAMIH and CEMEF, respectively. In a first preliminary step we simulate the drawing and extrusion operations in order to estimate the contact conditions in extrusion along the container and the die surfaces. Then by numerical simulation we estimate the contact conditions in the friction tests and define the parameters of the tests which insure the better similarity with the industrial operation. In the next step experiments will be performed in order to compare the results of these various friction tests.
\end{abstract}

Key words: Friction test, Extrusion, Cold Forging, Low Carbon Steel.

\section{INTRODUCTION}

The cold forging processes, including extrusion, drawing, upsetting, and heading, have been widely used to realize the net-shape manufacture in the transportation industry. The friction has a large effect on the cold forging, because it not only changes the forming force but also determines the surface quality of the formed part and dies life. The problem is especially critical in cold forging of steel which induces high contact pressure and new surface generation. So the billets are generally coated with zinc phosphate and soap and lubricated with oil to reduce the friction during forging [1].

For reduction of the cost and time of manufacture, almost all of manufacturers and research institutes use FE simulation to predict defects in the forged part and optimize the die shape. However, it is still difficult to choose the friction model and assign the friction coefficient. Therefore, several methods were invented to evaluate the friction condition during cold forging, such as ring compression, forward extrusion, upsetting-sliding test, spike test, double cup extrusion and T-shape compression. Studies illustrated that the contact surfaces in ring compression and spike test are shorn surfaces, which haven't been coated with phosphate/soap layer, so friction coefficient can not be adequately evaluated by using them. Forward extrusion and double cup extrusion [2] can induce the large contact pressure and new surface generation. Meanwhile, the load of forward extrusion and cup height ratio of double cup extrusion are sensitive to friction. In upsettingsliding test [3] friction coefficient is calculated starting from the tangential and normal forces of 
indenter. T-shape compression, a new friction test, was developed to evaluate the friction condition by using the formed part shape and compression load.

So four suitable methods, forward extrusion, doublecup extrusion, upsetting-sliding test and T-shape compression (see Fig. 1), can be chosen to determine friction coefficient in cold forging. However, each of them has special features and they haven't been compared. In this paper, we investigated their ability by $\mathrm{FE}$ simulation and evaluated the friction condition of an industrial cold extrusion process.

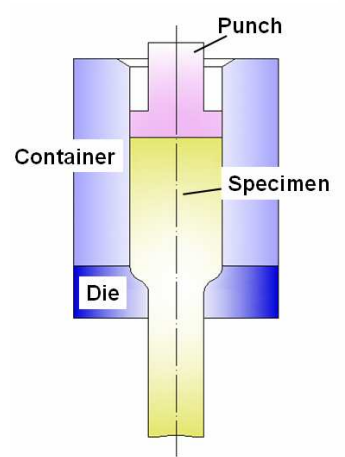

(a) Forward extrusion

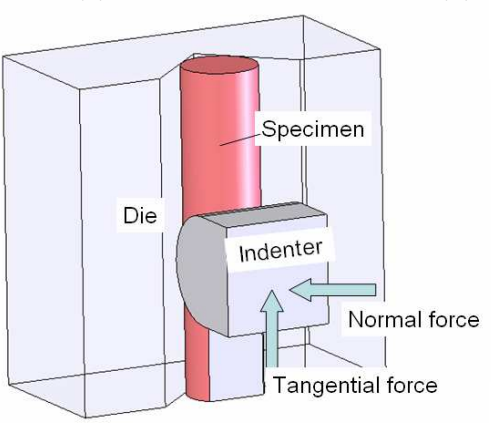

(c) Upsetting-sliding test

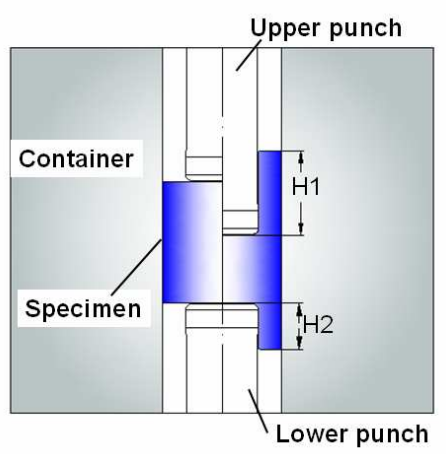

(b) Double-cup extrusion

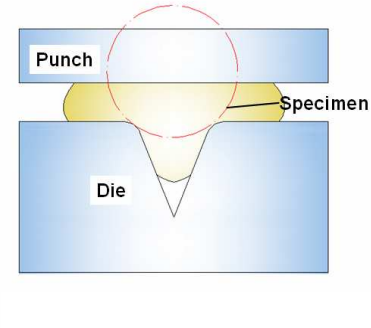

(d) T-shape compression Fig. 1 Friction tests for cold forging

\section{MATERIAL PROPERTY AND FRICTION LAW USED IN SIMULATION}

The material of specimen used in the simulation is low carbon AISI 1010 steel in drawn state. The relationship between strain and stress has been obtained by uniaxial compression test (Fig.1). For accurate simulation, several points on the strain/stress curve were chosen to input into the FE code, and we assume that the stress is constant, for strain higher than 0.7 .

There are two important laws, Coulomb and (Tresca) shear stress friction law, which are applied widely to calculate the tangential stress between specimen and tool in metal forming processes. Coulomb friction law was used in this work. It is because Coulomb friction law can be used in the high pressure condition, if the friction coefficient is small.

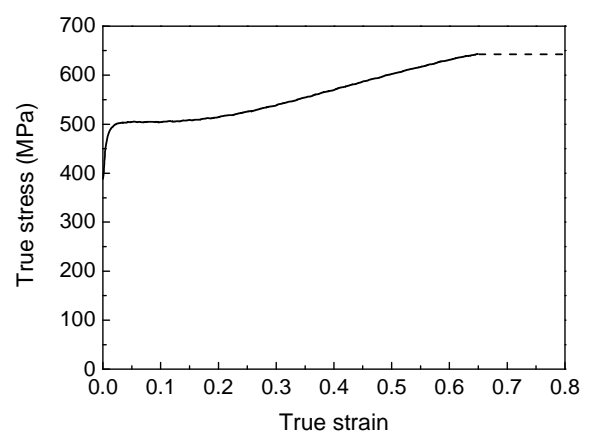

Fig. 1 The strain/stress curve of AISI 1010 by uniaxial compression test (drawn bar with $7.15 \mathrm{~mm}$ diameter)

\section{INDUSTRY COLD EXTRUSION PROCESS}

The whole manufacturing system includes drawing, cropping and extrusion processes. Cropping process can induce non-uniform shorn surface of billet and small deformation of billet, but it is not an important factor on friction. Therefore only drawing and extrusion processes were considered. That is AISI 1010 steel bar with $7.5 \mathrm{~mm}$ diameter was drawn to $7.15 \mathrm{~mm}$ diameter and then extruded to $4.43 \mathrm{~mm}$ (extrusion ratio $\lambda=2.6$ ) in a die with a complex shape. The axisymmetrical drawing and extrusion process were simulated by using FORGE2005®. According to the simulation results, the maximum contact pressure on the extrusion die can reach 2500 $\mathrm{MPa}$, whereas it is near $850 \mathrm{MPa}$ along the container. The equivalent strain in the extruded workpiece is 2 .

\section{FRICTION TESTS FOR COLD FORGING}

\subsection{Forward extrusion}

The operation is performed by a conical die with $29.6 \mathrm{deg}$ semi-angle and the extrusion ratio $\lambda$ equals to 1.96. The loading curve of forward extrusion is sensitive to the friction coefficient along the die and along the container. So the force can decrease with decreasing the length of workpiece in the container, whereas the die region has been filled with the metal. However, usually the friction coefficients on container and die are considered as equal despite the fact that some factors along container and die are different such as material, roughness, pressure and lubricant film thickness. For deeply investigating the friction on the extrusion, two different friction coefficients are assigned to 
contact pairs of die/workpiece and container/ workpiece (See Fig 1 (a)),

Fig. 3 shows the effect of friction coefficients of die and container on the extrusion loading curves. It is seen that the extrusion load changes by assigning different friction coefficient on die and container in simulation. After the extrusion experiment, the friction coefficient of container can be defined by the slope of the loading curve and that of die can be defined by the maximum load.

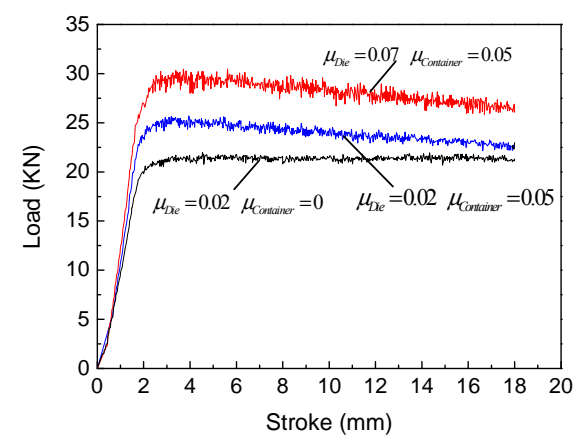

Fig. 3 Effect of friction coefficients of die and container on the extrusion loading curve

\subsection{Double-cup extrusion}

Double cup extrusion test includes four parts: upper punch, lower punch, container and specimen, as shown in Fig. 1 (b). In the test, the upper punch moves down with the press ram while the lower punch and container are stationary [2]. After extrusion, a part with two cups was formed. The height of upper cup H1 is larger than that of lower cup $\mathrm{H} 2$, because the container has relative velocity with respect to the upper punch, then the friction force from container promotes the metal flow into the upper cup. So the ratio of the upper cup height to the low cup height $(\mathrm{H} 1 / \mathrm{H} 2)$ was defined as cup height ratio, which can be used to determine the friction coefficient.

For the studied configuration, the ratio of the container diameter to the punch diameter is 1.66 . As in [2], we verified that the friction at the punch/billet interface has no significant influence on $\mathrm{H} 1 / \mathrm{H} 2$. Two kinds of material were chosen to simulate effect of strain hardening on cup height ratio, one is AISI 1010 (see Fig.2) and another is AISI 1010 without strain hardening. Simulation results illustrate the material strain hardening reduces significantly the cup height ratio (see Fig.4). It is because the difference in strain between both metal flows increases with the cup height ratio and so the strain hardening promotes its reduction. Therefore, in order to determine the friction coefficient by double cup extrusion, the material property, especially the strain/stress relationship, should be well-known and carefully assigned to FE model.

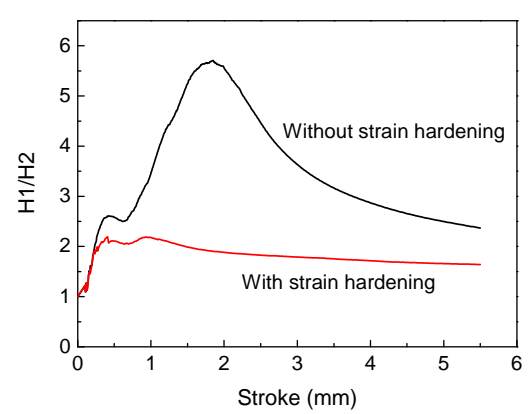

Fig.4 Effect of strain hardening on cup height ratio $(\mu=0.05)$

\subsection{Upsetting-sliding test}

The basic methodology of upsetting-sliding test is similar to the sliding indentation test. However it is special to simulate the real contact conditions of the drawing and extrusion processes [3]. As shown in Fig.1 (c), this test includes two main components: indenter and specimen. A cylindrical indenter plays a role of drawing or extrusion die, so the indenter is made with the same material and surface roughness than the die. The specimen with coating was fixed in the special device. Before test, the position of indenter is adjusted to induce the penetration depth $p$ of the indenter in the specimen. Then the indenter moves up with a constant tangential speed and scratches the surface of specimen. The forces in both normal $\left(F_{n}\right)$ and tangential $\left(F_{\tau}\right)$ directions are measured with load sensors and recorded in a computer to evaluate the friction condition between indenter and specimen [3].

In simulation, the radius of indenter was $5 \mathrm{~mm}$. Numerical simulation demonstrates that for a given penetration depth $p$, the force ratio $F_{\tau} / F_{n}$ increases with the friction coefficient $\mu$, but the contact pressure and the equivalent strain do not change significantly. Fig. 5 shows that the force ratio and the equivalent strain increase with increasing the penetration depth. The penetration depth of indenter in experiment can be decided depending on the equivalent strain of extrusion parts. Because equivalent strain in industrial extrusion part is 2 , the penetration depth of indenter should be chosen as $p=0.5 \mathrm{~mm}$ (see (Fig. 5). 


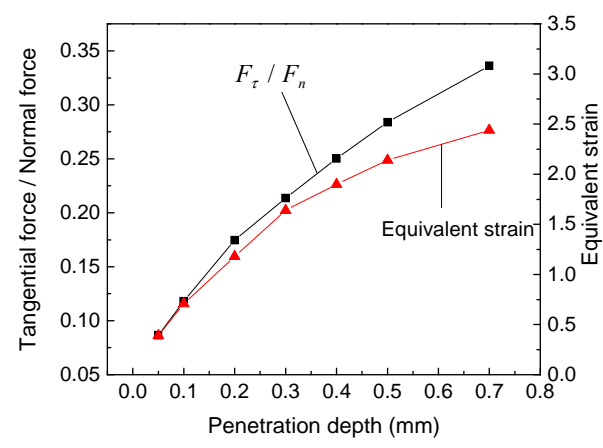

Fig. 5 Effects of the penetration depth of indenter on the force ratio and the equivalent strain $(\mu=0.02, R=5 \mathrm{~mm})$

\subsection{T-shape compression}

T-shape compression, a new method to determine friction coefficient in cold forging, is developed. The die in this test, is machined as a flat-topped die with a $\mathrm{V}$-shape groove (total angle $20 \mathrm{deg}, 7 \mathrm{~mm}$ depth and $1 \mathrm{~mm}$ entry radius) (see Fig. 1 (d)). With the flat upper punch moving down some metal of specimen will be extruded into the groove, others will be compressed between punch and die. The sectional shape of formed part in this test looks like ' $T$ ', suggesting us the name: T-shape compression test. The friction force generated between interface of billet and $\mathrm{V}$-shape wall can directly change load and the length $\mathrm{H}$ of the extrude part.

The stroke and load curves with different friction coefficient are shown in Fig. 6 (a). Results illustrate the load increases when increasing friction coefficient and the large stroke can improve the sensitivity of load to friction coefficient.
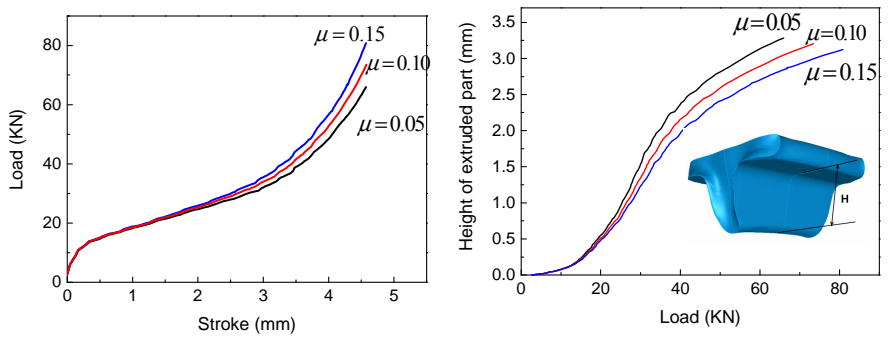

(a) Load

(b) Height of extrusion part

Fig. 6 Effects of friction coefficient on load and height of extrusion part

Fig. 6 (b) shows effect of friction coefficient on the height of extruded part. It is seen that the height of extruded part increases with decrease in the friction coefficient. Therefore, we can determine the friction condition in the T-shape compression by using compression load the deformed part shape.

\section{DISCUSSION AND CONCLUSION}

According to simulation of four kinds of friction tests, testing conditions of them are shown in table 1.

Table 1 Testing conditions for cold forging

\begin{tabular}{|c|c|c|c|}
\hline $\begin{array}{c}\text { Types of } \\
\text { testing }\end{array}$ & $\begin{array}{c}\text { Maximum } \\
\text { Pressure } \\
(\mathrm{MPa})\end{array}$ & $\begin{array}{c}\text { Maximum } \\
\text { equivalent } \\
\text { strain }\end{array}$ & $\begin{array}{c}\text { New surface } \\
\text { generation }\end{array}$ \\
\hline $\begin{array}{c}\text { Forward } \\
\text { extrusion }\end{array}$ & $\begin{array}{c}1800 \text { (die) } \\
\approx 500 \text { (cont.) }\end{array}$ & $\begin{array}{c}1.6 \text { (die) } \\
0 \text { (cont.) }\end{array}$ & $\begin{array}{c}40 \% \text { (die) } \\
0 \text { (cont.) }\end{array}$ \\
\hline $\begin{array}{c}\text { Double-cup } \\
\text { extrusion }\end{array}$ & 800 (cont.) & 1.9 (cont.) & $44 \%$ (cont.) \\
\hline $\begin{array}{c}\text { Upsetting- } \\
\text { sliding test }\end{array}$ & 1900 & 2.6 & $6.1 \%$ \\
\hline $\begin{array}{c}\text { T-shape } \\
\text { compression }\end{array}$ & 1900 & 3 & $50 \%$ \\
\hline $\begin{array}{c}\text { *Industry } \\
\text { extrusion }\end{array}$ & $\begin{array}{c}\mathbf{2 5 0 0} \text { (die) } \\
\mathbf{8 5 0} \text { (cont.) }\end{array}$ & $\begin{array}{c}\mathbf{2} \text { (die) } \\
\mathbf{0 . 1 5} \text { (cont.) }\end{array}$ & $\begin{array}{c}\mathbf{6 1} \% \\
\mathbf{0} \text { (cont.) }\end{array}$ \\
\hline
\end{tabular}

Concerning the main features of these tests, the friction conditions of die and container in forward extrusion may be different, because of different contact conditions. We can expect higher friction on the die in industry extrusion because contact pressure, equivalent strain and surface generation obtain highest values in die region. For double-cup extrusion material strain hardening has a large effect on the cup height ratio and determination of friction coefficient. In the upsetting-sliding test, the penetration depth of indenter can be defined by the equivalent strain of extruded part. In the T-shape compression, the friction coefficient can be determined by both compression load and shape of formed part. But according to table 1 we can find it is not possible to insure similar contact conditions for each test and industry extrusion. So experiments will demonstrate which contact parameters have significant influence on friction.

\section{ACKNOWLEDGEMENTS}

The authors want to thank the VIF (Virtual Intelligent Forging - CA) project for financing the research of friction condition in forging.

\section{REFERENCES}

1. N. Bay, The state of the art in cold forging lubrication. J. Mater. Process. Technol, 46 (1994) 19-40

2. T. Schrader, M. Shirgaokar, T. Altan. A critical evaluation of the double cup extrusion test for selection of cold forging lubricants, J. Mater. Process. Technol, 189 (2007) 36-44

3. L. Lazzarotto, L. Dubar, A. Dubois, et. al A selection methodology for lubricating oils in cold metal forming processes, Wear, 215 (1998) 1-9 